\title{
New Generalized Mixed Equilibrium Problem with Respect to Relaxed Semi-Monotone Mappings in Banach Spaces
}

\author{
Rabian Wangkeeree ${ }^{1,2}$ and Pakkapon Preechasilp ${ }^{1}$ \\ ${ }^{1}$ Department of Mathematics, Faculty of Science, Naresuan University, Phitsanulok 65000, Thailand \\ ${ }^{2}$ Centre of Excellence in Mathematics, CHE, Si Ayutthaya Road, Bangkok 10400, Thailand
}

Correspondence should be addressed to Rabian Wangkeeree, rabianw@nu.ac.th

Received 24 November 2011; Accepted 12 January 2012

Academic Editor: Yonghong Yao

Copyright (c) 2012 R. Wangkeeree and P. Preechasilp. This is an open access article distributed under the Creative Commons Attribution License, which permits unrestricted use, distribution, and reproduction in any medium, provided the original work is properly cited.

We introduce the new generalized mixed equilibrium problem with respect to relaxed semimonotone mappings. Using the KKM technique, we obtain the existence of solutions for the generalized mixed equilibrium problem in Banach spaces. Furthermore, we also introduce a hybrid projection algorithm for finding a common element in the solution set of a generalized mixed equilibrium problem and the fixed point set of an asymptotically nonexpansive mapping. The strong convergence theorem of the proposed sequence is obtained in a Banach space setting. The main results extend various results existing in the current literature.

\section{Introduction}

Let $E$ be a Banach space with the dual $E^{*}$ and let $E^{* *}$ denote the dual space of $E^{*}$. If $E=$ $E^{* *}$, then $E$ is called reflexive. We denote by $\mathcal{N}$ and $\mathcal{R}$ the sets of positive integers and real numbers, respectively. Also, we denote by $J$ the normalized duality mapping from $E$ to $2^{E^{*}}$ defined by

$$
J x=\left\{x^{*} \in E^{*}:\left\langle x, x^{*}\right\rangle=\|x\|^{2}=\left\|x^{*}\right\|^{2}\right\}, \quad \forall x \in E,
$$

where $\langle\cdot, \cdot\rangle$ denotes the generalized duality pairing. Recall that if $E$ is smooth, then $J$ is single-valued, and if $E$ is uniformly smooth, then $J$ is uniformly norm-to-norm continuous on bounded subsets of $E$. We shall still denote by $J$ the single-valued duality mapping. 
Let $C$ be a nonempty subset of $E^{* *}, \eta: C \times C \rightarrow E^{* *}$ be a mapping and let $\xi: E^{* *} \rightarrow R$ a function with $\xi(t z)=t^{p} \xi(z)$ for all $t>0$ and $z \in E^{* *}$, where $p>1$ is a constant. A mapping $A: C \times C \rightarrow E^{*}$ is said to be relaxed $\eta-\xi$ semimonotone [1] if the following two conditions hold:

(i) for each fixed $u \in C, A(u, \cdot)$ is relaxed $\eta-\xi$ monotone; that is,

$$
\langle A(u, v)-A(u, w), \eta(v, w)\rangle \geq \xi(v-w), \quad \forall v, w \in C
$$

(ii) for each fixed $v \in C, A(\cdot, v)$ is completely continuous; that is, for any net $\left\{u_{j}\right\}$ in $C, u_{j} \rightarrow u_{0}$ in weak ${ }^{*}$ topology of $E^{* *}$, then $\left\{A\left(u_{j}, v\right)\right\}$ has a subsequence $\left\{A\left(u_{j_{k}}, v\right)\right\} \rightarrow A\left(u_{0}, v\right)$ in norm topology of $E^{*}$.

In case $\eta(x, y)=x-y$ for all $x, y \in C$ and $\xi \equiv 0, A$ is called semi-monotone [2]. The following is an example of $\eta-\xi$ semi-monotone mapping.

Example 1.1. Let $C=(-\infty, \infty), A(x, y)=x+y$, and

$$
\eta(x, y)= \begin{cases}-c(x-y), & x \geq y \\ c(x-y), & x<y\end{cases}
$$

where $c>0$ is a constant. Then, $A$ is relaxed $\eta-\xi$ semi-monotone with

$$
\xi(z)= \begin{cases}-c z^{2}, & z \geq 0 \\ c z^{2}, & z<0 .\end{cases}
$$

Let $f: C \times C \rightarrow \mathcal{R}$ be a bifunction, $\eta: C \times C \rightarrow E^{* *}$ a mapping, and $\xi: E^{* *} \rightarrow \mathcal{R}$, $\varphi: C \rightarrow \mathcal{R}$ two real-valued functions, and let $A: C \times C \rightarrow E^{*}$ be a $\eta-\xi$ semi-monotone mapping. We consider the problem of finding $u \in C$ such that

$$
f(u, v)+\langle A(u, u), \eta(v, u)\rangle+\varphi(v) \geq \varphi(u), \quad \forall v \in C,
$$

which is called the generalized mixed equilibrium problem with respect to relaxed $\eta$ - $\xi$ semi-monotone mapping $(\operatorname{GMEP}(f, A, \eta, \varphi))$. The set of such $u \in C$ is denoted by $\operatorname{GMEP}(f, A, \eta, \varphi)$, that is,

$$
\operatorname{GMEP}(f, A, \eta, \varphi)=\{u \in C: f(u, v)+\langle A(u, u), \eta(v, u)\rangle+\varphi(v) \geq \varphi(u), \forall v \in C\}
$$

Now, let us consider some special cases of the problem (1.5).

(a) In the case of $f \equiv 0,(1.5)$ is deduced to the following variational-like inequality problem:

find $u \in C$ such that $\langle A(u, u), \eta(v, u)\rangle+\varphi(v)-\varphi(u) \geq 0, \quad \forall v \in C$. 
The problem (1.7) was studied by Fang and Huang [1]. Using the KKM technique and $\eta-\xi$ monotonicity of the mapping $\varphi$, they [1] obtained the existence of solutions of the variationallike inequality problem (1.7) in a real Banach space.

(b) In the case of $f \equiv 0, \varphi \equiv 0$ and $\eta(v, u)=v-u$ for all $v, u \in C$, the problem (1.5) is deduced to the following variational inequality problem:

Find $u \in C$ such that $\langle A(u, u), v-u\rangle \geq 0, \quad \forall v \in C$.

The problem (1.8) was studied by Chen [2]. They obtained the existence results of solutions in a real Banach space.

When $E$ is a reflexive Banach space, we know $E^{* *}=j(E)$, where $j: E \rightarrow E^{* *}$ is the duality mapping defined by $\langle j x, f\rangle=\langle f, x\rangle$, for all $x \in E, f \in E^{*}$, which is an isometric mapping, so we may regard $E=E^{* *}$ under an isometry. The following problems can be derived as special cases of the problem (1.5).

(c) In case $E$ is reflexive (i.e., $\left.E=E^{* *}\right), f \equiv 0$ and $\eta(v, u)=v-u$ for all $v, u \in C$, the problem (1.5) is deduced to the following variational inequality problem:

find $u \in C$ such that $\langle A(u, u), v-u\rangle+\varphi(v)-\varphi(u) \geq 0, \quad \forall v \in C$.

The problem (1.9) was studied by Chen [2].

(d) If $E$ is reflexive (i.e., $E=E^{* *}$ ) and $A \equiv 0,(1.5)$ is deduced to the mixed equilibrium problem:

$$
\text { find } u \in C \text { such that } f(u, v)+\varphi(v) \geq \varphi(u), \quad \forall v \in C \text {. }
$$

The problem (1.10) was considered and studied by Ceng and Yao [3]; Cholamjiak and Suantai [4].

(e) In the case of $A \equiv 0$ and $\varphi \equiv 0,(1.5)$ is deduced to the following classical equilibrium problem:

$$
\text { find } u \in C \text { such that } f(u, v) \geq 0, \quad \forall v \in C \text {. }
$$

The set of all solution of (1.11) is denoted by $\operatorname{EP}(f)$, that is,

$$
\operatorname{EP}(f)=\{u \in C: f(u, v) \geq 0, \quad \forall v \in C\} .
$$

Numerous problems in physics, optimization, and economics can be reduced to find a solution of the equilibrium problem, variational inequality problem, and related optimization problems; see, for instance, [5-11]. Some methods have been proposed to solve the equilibrium problem in a Hilbert space; see, for instance, Blum and Oettli [12]; Combettes and Hirstoaga [13]; Moudafi [14]. 
Let $C$ be a nonempty, closed convex subset of $E$. A mapping $S: C \rightarrow E$ is called nonexpansive if $\|S x-S y\| \leq\|x-y\|$ for all $x, y \in C$. Also a mapping $S: C \rightarrow C$ is called asymptotically nonexpansive if there exists a sequence $\left\{k_{n}\right\} \subset[1, \infty)$ with $k_{n} \rightarrow 1$ as $n \rightarrow \infty$ such that $\left\|S^{n} x-S^{n} y\right\| \leq k_{n}\|x-y\|$ for all $x, y \in C$ and for each $n \geq 1$. The class of asymptotically nonexpansive mappings was introduced by Goebel and Kirk [15] as an important generalization of nonexpansive mappings. Denote by $F(S)$ the set of fixed points of $S$, that is, $F(S)=\{x \in C: S x=x\}$. There are several methods for approximating fixed points of a nonexpansive mapping; see, for instance, [16-21]. Furthermore, since 1972, a host of authors have studied weak and strong convergence problems of the iterative processes for the class of asymptotically nonexpansive mappings; see, for instance, [22-25]. In 1953, Mann [16] introduced the following iterative procedure to approximate a fixed point of a nonexpansive mapping $S$ in a Hilbert space $H$ :

$$
x_{n+1}=\alpha_{n} x_{n}+\left(1-\alpha_{n}\right) S x_{n}, \quad \forall n \in \mathcal{N}
$$

where the initial point $x_{0}$ is taken in $C$ arbitrarily and $\left\{\alpha_{n}\right\}$ is a sequence in $[0,1]$. However, we note that Mann's iteration process (1.13) has only weak convergence, in general; for instance, see [26-28]. In 2003, Nakajo and Takahashi [29] introduced the following iterative algorithm for the nonexpansive mapping $S$ in the framework of Hilbert spaces:

$$
\begin{gathered}
x_{0}=x \in C, \\
y_{n}=\alpha_{n} x_{n}+\left(1-\alpha_{n}\right) S x_{n}, \\
C_{n}=\left\{z \in C:\left\|z-y_{n}\right\| \leq\left\|z-x_{n}\right\|\right\}, \\
Q_{n}=\left\{z \in C:\left\langle x_{n}-z, x-x_{n}\right\rangle \geq 0\right\}, \\
x_{n+1}=P_{C_{n} \cap Q_{n}} x, \quad n \geq 0,
\end{gathered}
$$

where $\left\{\alpha_{n}\right\} \subset[0, \alpha], \alpha \in[0,1]$, and $P_{C_{n} \cap Q_{n}}$ is the metric projection from a Hilbert space $H$ onto $C_{n} \cap Q_{n}$. They proved that $\left\{x_{n}\right\}$ generated by (1.14) converges strongly to a fixed point of $S$. $\mathrm{Xu}$ [30] extended Nakajo and Takahashi's theorem to Banach spaces by using the generalized projection.

Matsushita and Takahashi [17] introduced the following iterative algorithm in the framework of Banach spaces:

$$
\begin{gathered}
x_{0}=x \in C, \\
C_{n}=\overline{\mathrm{co}}\left\{z \in C:\|z-S z\| \leq t_{n}\left\|x_{n}-S x_{n}\right\|\right\}, \\
D_{n}=\left\{z \in C:\left\langle x_{n}-z, J\left(x-x_{n}\right)\right\rangle \geq 0\right\}, \\
x_{n+1}=P_{C_{n} \cap D_{n}} x, \quad n \geq 0,
\end{gathered}
$$

where $\overline{\mathrm{co}} D$ denoted the convex closure of the set $D,\left\{t_{n}\right\}$ is a sequence in $(0,1)$ with $t_{n} \rightarrow 0$, and $P_{C_{n} \cap D_{n}}$ is the metric projection from $E$ onto $C_{n} \cap D_{n}$. 
Very recently, Dehghan [24] introduced the following iterative algorithm for finding fixed points of an asymptotically nonexpansive mapping $S$ in a uniformly convex and smooth Banach space:

$$
\begin{gathered}
x_{0}=x \in C, \quad C_{0}=D_{0}=C, \\
C_{n}=\overline{\mathrm{co}}\left\{z \in C_{n-1}:\left\|z-S^{n} z\right\| \leq t_{n}\left\|x_{n}-S^{n} x_{n}\right\|\right\}, \\
D_{n}=\left\{z \in D_{n-1}:\left\langle x_{n}-z, J\left(x-x_{n}\right)\right\rangle \geq 0\right\}, \\
x_{n+1}=P_{C_{n} \cap D_{n}} x, \quad n \geq 0,
\end{gathered}
$$

where $\overline{\mathrm{co}} D$ denotes the convex closure of the set $D, J$ is the normalized duality mapping, $\left\{t_{n}\right\}$ is a sequence in $(0,1)$ with $t_{n} \rightarrow 0$, and $P_{C_{n} \cap D_{n}}$ is the metric projection from $E$ onto $C_{n} \cap D_{n}$. The strong convergence theorem of the iterative sequence $\left\{x_{n}\right\}$ defined by (1.16) is obtained in a uniformly convex and smooth Banach space.

In this paper, motivated and inspired by the above results, we first suggest and analyze the new generalized mixed equilibrium problem with respect to relaxed $\eta-\xi$ semi-monotone mapping. Using the KKM technique, we obtain the existence of solutions for such problem in a Banach space. Next, we also introduce a hybrid projection algorithm for finding a common element in the solution set of a generalized mixed equilibrium problem and the fixed point set of an asymptotically nonexpansive mapping. The strong convergence theorem of the proposed sequence is obtained in a Banach space setting. The main results extend various results existing in the current literature.

\section{Preliminaries}

Let $E$ be a real Banach space, and let $U=\{x \in E:\|x\|=1\}$ be the unit sphere of $E$. A Banach space $E$ is said to be strictly convex if for any $x, y \in U$,

$$
x \neq y \text { implies }\|x+y\|<2 .
$$

It is also said to be uniformly convex if for each $\varepsilon \in(0,2]$, there exists $\delta>0$ such that for any $x, y \in U$,

$$
\|x-y\| \geq \varepsilon \text { implies }\|x+y\|<2(1-\delta)
$$

It is known that a uniformly convex Banach space is reflexive and strictly convex. Define a function $\delta:[0,2] \rightarrow[0,1]$ called the modulus of convexity of $E$ as follows:

$$
\delta(\varepsilon)=\inf \left\{1-\left\|\frac{x+y}{2}\right\|: x, y \in E,\|x\|=\|y\|=1,\|x-y\| \geq \varepsilon\right\} .
$$


Then $E$ is uniformly convex if and only if $\delta(\varepsilon)>0$ for all $\varepsilon \in(0,2]$. A Banach space $E$ is said to be smooth if the limit

$$
\lim _{t \rightarrow 0} \frac{\|x+t y\|-\|x\|}{t}
$$

exists for all $x, y \in U$. Let $C$ be a nonempty, closed, and convex subset of a reflexive, strictly convex, and smooth Banach space $E$. Then for any $x \in E$, there exists a unique point $x_{0} \in C$ such that

$$
\left\|x_{0}-x\right\| \leq \min _{y \in C}\|y-x\|
$$

The mapping $P_{C}: E \rightarrow C$ defined by $P_{C} x=x_{0}$ is called the metric projection from $E$ onto $C$. The following theorem is wellknown.

Theorem 2.1 (see [31]). Let $C$ be a nonempty, closed convex subset of a smooth Banach space $E$ and let $x \in E$, and $y \in C$. Then the following are equivalent:

(a) $y$ is a best approximation to $x: y=P_{C} x$.

(b) $y$ is a solution of the variational inequality:

$$
\langle y-z, J(x-y)\rangle \geq 0, \quad \forall z \in C
$$

where $J$ is a duality mapping and $P_{C}$ is the metric projection from $E$ onto $C$.

It is wellknown that if $P_{C}$ is a metric projection from a real Hilbert space $H$ onto a nonempty, closed, and convex subset $C$, then $P_{C}$ is nonexpansive. But, in a general Banach space, this fact is not true.

In the sequel, we will need the following lemmas.

Lemma 2.2 (see [32]). Let E be a uniformly convex Banach space, let $\left\{\alpha_{n}\right\}$ be a sequence of real numbers such that $0<b \leq \alpha_{n} \leq c<1$ for all $n \geq 1$, and let $\left\{x_{n}\right\}$ and $\left\{y_{n}\right\}$ be sequences in $E$ such that $\lim \sup _{n \rightarrow \infty}\left\|x_{n}\right\| \leq d$, $\lim \sup _{n \rightarrow \infty}\left\|y_{n}\right\| \leq d$, and $\lim _{n \rightarrow \infty}\left\|\alpha_{n} x_{n}+\left(1-\alpha_{n}\right) y_{n}\right\|=d$. Then $\lim _{n \rightarrow \infty}\left\|x_{n}-y_{n}\right\|=0$.

Theorem 2.3 (see [33]). Let C be a bounded, closed, and convex subset of a uniformly convex Banach space $E$. Then there exists a strictly increasing, convex, and continuous function $\gamma:[0, \infty) \rightarrow[0, \infty)$ such that $\gamma(0)=0$ and

$$
r\left(\left\|S\left(\sum_{i=1}^{n} \lambda_{i} x_{i}\right)-\sum_{i=1}^{n} \lambda_{i} S x_{i}\right\|\right) \leq \max _{1 \leq j \leq k \leq n}\left(\left\|x_{j}-x_{k}\right\|-\left\|S x_{j}-S x_{k}\right\|\right)
$$

for all $n \in \mathcal{N},\left\{x_{1}, x_{2}, \ldots, x_{n}\right\} \subset C,\left\{\lambda_{1}, \lambda_{2}, \ldots, \lambda_{n}\right\} \subset[0,1]$ with $\sum_{i=1}^{n} \lambda_{i}=1$ and nonexpansive mapping $S$ of $C$ into $E$. 
Theorem 2.4 (see [24]). Let C be a bounded, closed, and convex subset of a uniformly convex Banach space $E$. Then there exists a strictly increasing, convex, and continuous function $\gamma:[0, \infty) \rightarrow[0, \infty)$ such that $\gamma(0)=0$ and

$$
r\left(\frac{1}{k_{m}}\left\|S^{m}\left(\sum_{i=1}^{n} \lambda_{i} x_{i}\right)-\sum_{i=1}^{n} \lambda_{i} S^{m} x_{i}\right\|\right) \leq \max _{1 \leq j \leq k \leq n}\left(\left\|x_{j}-x_{k}\right\|-\frac{1}{k_{m}}\left\|S^{m} x_{j}-S^{m} x_{k}\right\|\right),
$$

for all $n \in \mathcal{N},\left\{x_{1}, x_{2}, \ldots, x_{n}\right\} \subset C ;\left\{\lambda_{1}, \lambda_{2}, \ldots, \lambda_{n}\right\} \subset[0,1]$ with $\sum_{i=1}^{n} \lambda_{i}=1$ and an asymptotically nonexpansive mapping $S$ of $C$ into $E$ with the sequence $\left\{k_{m}\right\}$.

Now, let us recall the following well-known concepts and results.

Definition 2.5. Let $B$ be a subset of topological vector space $X$. A mapping $G: B \rightarrow 2^{X}$ is called a KKM mapping if $\operatorname{co}\left\{x_{1}, x_{2}, \ldots, x_{m}\right\} \subset \bigcup_{i=1}^{m} G\left(x_{i}\right)$ for $x_{i} \in B$ and $i=1,2, \ldots, m$, where $\operatorname{co} A$ denotes the convex hull of the set $A$.

Lemma 2.6 (see [34]). Let $B$ be a nonempty subset of a Hausdorff topological vector space $X$, and let $G: B \rightarrow 2^{X}$ be a KKM mapping. If $G(x)$ is closed for all $x \in B$ and is compact for at least one $x \in B$, then $\bigcap_{x \in B} G(x) \neq \emptyset$.

Theorem 2.7 (see [35] (Kakutani-Fan-Glicksberg Fixed Point Theorem)). Let E be a locally convex Hausdorff topological vector space and $C$ a nonempty, convex, and compact subset of $E$. Suppose $T: C \rightarrow 2^{C}$ is a upper semi-continuous mapping with nonempty, closed, and convex values. Then $T$ has a fixed point in $C$.

Definition 2.8 (see [36]). Let $C$ be a nonempty, closed convex of a Banach space $E$. Let $T: C \rightarrow$ $E^{*}$ and let $\eta: C \times C \rightarrow R$ be two mappings. $T$ is said to be $\eta$-hemicontinuous if, for any fixed $x, y \in C$, the mapping $f:[0,1] \rightarrow(-\infty, \infty)$ defined by $f(t)=\langle T(x+t(y-x)), \eta(y, x)\rangle$ is continuous at $0^{+}$.

For solving the mixed equilibrium problem, let us assume the following conditions for a bifunction $f: C \times C \rightarrow R$ :

(A1) $f(x, x)=0$ for all $x \in C$;

(A2) $f$ is monotone, that is, $f(x, y)+f(y, x) \leq 0$ for all $x, y \in C$;

(A3) for all $y \in C, f(\cdot, y)$ is weakly upper semicontinuous;

(A4) for all $x \in C, f(x, \cdot)$ is convex.

The following lemmas can be found in [37].

Lemma 2.9 (see [37]). Let $C$ be a nonempty, bounded, closed, and convex subset of a smooth, strictly convex and reflexive Banach space $E$, let $T: C \rightarrow E^{*}$ be an $\eta$-hemicontinuous and relaxed $\eta-\xi$ monotone mapping. Let $f$ be a bifunction from $C \times C$ to $R$ satisfying (A1) and (A4), and let $\varphi$ be a lower semicontinuous and convex function from $C$ to $R$. Let $r>0$ and $z \in C$. Assume that

(i) $\eta(x, x)=0$, for all $x \in C$;

(ii) for any fixed $u, v \in C$, the mapping $x \mapsto\langle T v, \eta(x, u)\rangle$ is convex. 
Then the following problems (2.9) and (2.10) are equivalent. Find $x \in C$ such that:

$$
f(x, y)+\varphi(y)+\langle T x, \eta(y, x)\rangle+\frac{1}{r}\langle y-x, J(x-z)\rangle \geq \varphi(x), \quad \forall y \in C .
$$

Find $x \in C$ such that

$$
f(x, y)+\langle T y, \eta(y, x)\rangle+\varphi(y)+\frac{1}{r}\langle y-x, J(x-z)\rangle \geq \varphi(x)+\xi(y-x), \quad \forall y \in C .
$$

Lemma 2.10 (see [37]). Let $C$ be a nonempty, bounded, closed, and convex subset of a smooth, strictly convex, and reflexive Banach space $E$, let $T: C \rightarrow E^{*}$ be an $\eta$-hemicontinuous and relaxed $\eta-\xi$ monotone mapping. Let $f$ be a bifunction from $C \times C$ to $R$ satisfying (A1), (A3), and (A4), and let $\varphi$ be a lower semicontinuous and convex function from $C$ to $R$. Let $r>0$ and $z \in C$. Assume that

(i) $\eta(x, y)+\eta(y, x)=0$ for all $x, y \in C$;

(ii) for any fixed $u, v \in C$, the mapping $x \mapsto\langle T v, \eta(x, u)\rangle$ is convex and lower semicontinuous;

(iii) $\xi: E \rightarrow \mathcal{R}$ is weakly lower semicontinuous; that is, for any net $\left\{x_{\beta}\right\},\left\{x_{\beta}\right\}$ converges to $x$ in $\sigma\left(E, E^{*}\right)$ implies that $\xi(x) \leq \liminf \xi\left(x_{\beta}\right)$.

Then, the solution set of the problem (2.9) is nonempty, that is, there exists $x_{0} \in C$ such that

$$
f\left(x_{0}, y\right)+\left\langle T x_{0}, \eta\left(y, x_{0}\right)\right\rangle+\varphi(y)+\frac{1}{r}\left\langle y-x_{0}, J\left(x_{0}-z\right)\right\rangle \geq \varphi\left(x_{0}\right), \quad \forall y \in C
$$

\section{Existence Results of Generalized Mixed Equilibrium Problem}

In this section, we prove the following crucial lemma concerning the generalized mixed equilibrium problem with respect to relaxed $\eta$ - $\xi$ semi-monotone mapping $(\operatorname{GMEP}(f, A, \eta, \varphi))$ in a real Banach space with the smooth and strictly convex second dual space.

Lemma 3.1. Let $E$ be a real Banach space with the smooth and strictly convex second dual space $E^{* *}$, let $C$ be a nonempty bounded closed convex subset of $E^{* *}$, let $A: C \times C \rightarrow E^{*}$ be a relaxed $\eta-\xi$ semi-monotone mapping. Let $f: C \times C \rightarrow R$ be a bifunction satisfying (A1), (A3), and (A4), and let $\varphi: C \rightarrow \mathcal{R} \cup\{+\infty\}$ be a proper lower semicontinuous and convex function. Let $r>0$ and $z \in C$. Assume that

(i) $\eta(x, y)+\eta(y, x)=0$ for all $x, y \in C$;

(ii) for any fixed $u, v, w \in C$, the mapping $x \mapsto\langle A(v, w), \eta(x, u)\rangle$ is convex and lower semicontinuous;

(iii) for each $x \in C, A(x, \cdot): C \rightarrow E^{*}$ is finite-dimensional continuous: that is, for any finitedimensional subspace $F \subset E^{* *}, A(x, \cdot): C \cap F \rightarrow E^{*}$ is continuous;

(iv) $\xi: E^{* *} \rightarrow \mathcal{R}$ is convex lower semicontinuous.

Then there exists $u_{0} \in C$ such that

$$
f\left(u_{0}, v\right)+\left\langle A\left(u_{0}, u_{0}\right), \eta\left(v, u_{0}\right)\right\rangle+\varphi(v)+\frac{1}{r}\left\langle v-u_{0}, J\left(u_{0}-z\right)\right\rangle \geq \varphi\left(u_{0}\right), \quad \forall v \in C
$$


Proof. Let $F \subseteq E^{* *}$ be a finite-dimensional subspace with $C_{F}:=F \cap C \neq \emptyset$. For each $w \in C$, consider the following problem: find $u_{0} \in C_{F}$ such that

$$
f\left(u_{0}, v\right)+\left\langle A\left(w, u_{0}\right), \eta\left(v, u_{0}\right)\right\rangle+\varphi(v)+\frac{1}{r}\left\langle v-u_{0}, J\left(u_{0}-z\right)\right\rangle-\varphi\left(u_{0}\right) \geq 0, \quad \forall v \in C_{F} .
$$

Since $C_{F} \subseteq F$ is bounded closed and convex, $A(w, \cdot)$ is continuous on $C_{F}$ and relaxed $\eta-\xi$ monotone for each fixed $w \in C$, from Lemma 2.10, we know that problem (3.2) has a solution $u_{0} \in C_{F}$.

Now, define a set-valued mapping $G: C_{F} \rightarrow 2^{C_{F}}$ as follows:

$$
\mathrm{Gw}=\left\{u \in C_{F}: f(u, v)+\langle A(w, u), \eta(v, u)\rangle+\varphi(v)+\frac{1}{r}\langle v-u, J(u-z)\rangle-\varphi(u) \geq 0, \forall v \in C_{F}\right\} .
$$

It follows from Lemma 2.9 that, for each fixed $w \in C_{F}$ :

$$
\begin{aligned}
\{u \in & \left.C_{F}: f(u, v)+\langle A(w, u), \eta(v, u)\rangle+\varphi(v)+\frac{1}{r}\langle v-u, J(u-z)\rangle-\varphi(u) \geq 0, \forall v \in K_{F}\right\} \\
& =\left\{u \in C_{F}: f(u, v)+\langle A(w, v), \eta(v, u)\rangle+\varphi(v)+\frac{1}{r}\langle v-u, J(u-z)\rangle-\varphi(u) \geq \xi(v-u), \forall v \in K_{F}\right\} .
\end{aligned}
$$

Since every convex lower semicontinuous function in Banach spaces is weakly lower semicontinuous, the proper convex lower semicontinuity of $\varphi$ and $\xi$, condition (ii), (A3) and (A4) implies that $G: C_{F} \rightarrow 2^{C_{F}}$ has nonempty bounded closed and convex values. Using (A3) and the complete continuity of $A(\cdot, u)$, we can conclude that $G$ is upper semicontinuous. It follows from Theorem 2.7 that $G$ has a fixed point $w^{*} \in C_{F}$, that is,

$$
\left\langle f\left(w^{*}, v\right)+\left\langle A\left(w^{*}, w^{*}\right), \eta\left(v, w^{*}\right)\right\rangle+\varphi(v)+\frac{1}{r}\left\langle v-w^{*}, J\left(w^{*}-z\right)\right\rangle-\varphi\left(w^{*}\right) \geq 0, \quad \forall v \in C_{F} .\right.
$$

Let

$$
\mathcal{F}=\left\{F \subset E^{* *}: F \text { is finite dimensional with } F \cap C \neq \emptyset\right\},
$$

and let

$$
\begin{aligned}
W_{F}=\{u \in C: f(u, v)+\langle A(u, v), \eta(v, u)\rangle+\varphi(v) \\
\left.\quad+\frac{1}{\mathrm{r}}\langle v-u, J(u-z)\rangle-\varphi(u) \geq \xi(v-u), \forall v \in C_{F}\right\}, \quad \forall F \in \mathcal{F} .
\end{aligned}
$$


By (3.5) and Lemma 2.9, we know that $W_{F}$ is nonempty and bounded. Denote by $\bar{W}_{F}^{*}$ the weak ${ }^{*}$-closure of $W_{F}$ in $E^{* *}$. Then, $\bar{W}_{F}^{*}$ is weak ${ }^{*}$ compact in $E^{* *}$.

For any $F_{i} \in \mathcal{F}, i=1,2, \ldots, N$, we know that $W_{\bigcap_{i=1}^{N} F_{i}} \subset \bigcap_{i=1}^{N} W_{F_{i}}$, so $\left\{\bar{W}_{F}^{*}: F \in \mathcal{F}\right\}$ has the finite intersection property. Therefore, it follows that

$$
\bigcap_{F \in \mathscr{F}} \bar{W}_{F}^{*} \neq \emptyset
$$

Let $u_{0} \in \bigcap_{F \in \mathcal{F}} \bar{W}_{F}^{*}$. We claim that

$$
f\left(u_{0}, v\right)+\left\langle A\left(u_{0}, u_{0}\right), \eta\left(v, u_{0}\right)\right\rangle+\varphi(v)+\frac{1}{r}\left\langle v-u_{0}, J\left(u_{0}-z\right)\right\rangle-\varphi\left(u_{0}\right) \geq 0, \quad \forall v \in C .
$$

Indeed, for each $v \in C$, let $F \in \mathcal{F}$ be such that $v \in C_{F}$ and $u_{0} \in C_{F}$. Then, there exists $u_{j} \in W_{F}$ such that $u_{j} \rightarrow u_{0}$. The definition of $W_{F}$ implies that

$$
f\left(u_{j}, v\right)+\left\langle A\left(u_{j}, v\right), \eta\left(v, u_{j}\right)\right\rangle+\varphi(v)+\frac{1}{r}\left\langle v-u_{j}, J\left(u_{j}-z\right)\right\rangle-\varphi\left(u_{j}\right) \geq \xi\left(v-u_{j}\right),
$$

that is

$$
f\left(u_{j}, v\right)+\left\langle A\left(u_{j}, v\right), \eta\left(v, u_{j}\right)\right\rangle+\varphi(v)+\frac{1}{r}\left\langle v-z, J\left(u_{j}-z\right)\right\rangle-\frac{1}{r}\left\|z-u_{j}\right\|^{2}-\varphi\left(u_{j}\right) \geq \xi\left(v-u_{j}\right)
$$

for all $j=1,2, \ldots$. Using the complete continuity of $A(\cdot, u),(\mathrm{A} 3)$, (ii), the continuity of $J$, the convex lower semicontinuity of $\varphi, \xi$, and $\|\cdot\|^{2}$, and letting $j \rightarrow \infty$, we get

$$
f\left(u_{0}, v\right)+\left\langle A\left(u_{0}, v\right), \eta\left(v, u_{0}\right)\right\rangle+\varphi(v)+\frac{1}{r}\left\langle v-u_{0}, J\left(u_{0}-z\right)\right\rangle-\varphi\left(u_{0}\right) \geq \xi\left(v-u_{0}\right), \quad \forall v \in C
$$

From Lemma 2.9, we have

$$
f\left(u_{0}, v\right)+\left\langle A\left(u_{0}, u_{0}\right), \eta\left(v, u_{0}\right)\right\rangle+\varphi(v)+\frac{1}{r}\left\langle v-u_{0}, J\left(u_{0}-z\right)\right\rangle-\varphi\left(u_{0}\right) \geq 0, \quad \forall v \in C .
$$

Hence, we complete the proof.

Setting $A \equiv 0$ and $\varphi \equiv 0$ in Lemma 3.1, we have the following result. 
Corollary 3.2. Let $E$ be a real Banach space with the smooth and strictly convex second dual space $E^{* *}$, let $C$ be a nonempty bounded closed convex subset of $E^{* *}$. Let $f: C \times C \rightarrow R$ be a bifunction satisfying (A1), (A3), and (A4). Let $r>0$ and $z \in C$. Then there exists $u_{0} \in C$ such that

$$
f\left(u_{0}, v\right)+\frac{1}{r}\left\langle v-u_{0}, J\left(u_{0}-z\right)\right\rangle \geq 0, \quad \forall v \in C
$$

If $E$ is reflexive (i.e., $E=E^{* *}$ ) smooth and strictly convex real Banach space, then we have the following result.

Corollary 3.3. Let $E$ be a reflexive smooth and strictly convex Banach space, let $C$ be a nonempty bounded closed convex subset of $E$, let $A: C \times C \rightarrow E^{*}$ be a relaxed $\eta$ - $\xi$ semi-monotone mapping. Let $f: C \times C \rightarrow R$ be a bifunction satisfying (A1), (A3), and (A4), and let $\varphi: C \rightarrow R \cup\{+\infty\}$ be a proper lower semicontinuous and convex function. Let $r>0$ and $z \in C$. Assume that

(i) $\eta(x, y)+\eta(y, x)=0$ for all $x, y \in C$;

(ii) for any fixed $u, v, w \in C$, the mapping $x \mapsto\langle A(v, w), \eta(x, u)\rangle$ is convex and lower semicontinuous;

(iii) for each $x \in C, A(x, \cdot): C \rightarrow E^{*}$ is finite-dimensional continuous.

(iv) $\xi: E \rightarrow R$ is convex lower semicontinuous.

Then, there exists $u_{0} \in C$ such that

$$
f\left(u_{0}, v\right)+\left\langle A\left(u_{0}, u_{0}\right), \eta\left(v, u_{0}\right)\right\rangle+\varphi(v)+\frac{1}{r}\left\langle v-u_{0}, J\left(u_{0}-z\right)\right\rangle \geq \varphi\left(u_{0}\right), \quad \forall v \in C .
$$

If $E$ is reflexive (i.e., $E=E^{* *}$ ) smooth and strictly convex, $A$ is semi-monotone, then we obtain the following result.

Corollary 3.4. Let $E$ be a reflexive smooth and strictly convex Banach space, let $C$ be a nonempty bounded closed convex subset of $E$, let $A: C \times C \rightarrow E^{*}$ be a semi-monotone mapping. Let $f$ : $C \times C \rightarrow R$ be a bifunction satisfying (A1), (A3), and (A4), and let $\varphi: C \rightarrow \mathcal{R} \cup\{+\infty\}$ be a proper lower semicontinuous and convex function. Assume that, for any $r>0$ and $z \in C$,

(i) for any fixed $u, v, w \in C$, the mapping $x \mapsto\langle A(v, w), x-u)\rangle$ is convex and lower semicontinuous;

(ii) for each $x \in C, A(x, \cdot): C \rightarrow E^{*}$ is finite-dimensional continuous.

Then, there exists $u_{0} \in C$ such that

$$
f\left(u_{0}, v\right)+\left\langle A\left(u_{0}, u_{0}\right), v-u_{0}\right\rangle+\varphi(v)+\frac{1}{r}\left\langle v-u_{0}, J\left(u_{0}-z\right)\right\rangle \geq \varphi\left(u_{0}\right), \quad \forall v \in C
$$

Theorem 3.5. Let $E$ be a real Banach space with the smooth and strictly convex second dual space $E^{* *}$, let $C$ be a nonempty, bounded, closed, and convex subset of $E^{* *}$, let $A: C \times C \rightarrow E^{*}$ be a relaxed $\eta$ - $\xi$ semi-monotone mapping. Let $f$ be a bifunction from $C \times C$ to $R$ satisfying (A1)-(A4) and let 
$\varphi$ be a lower semicontinuous and convex function from $C$ to $R$. For any $r>0$, define a mapping $\Phi_{r}: E^{* *} \rightarrow C$ as follows:

$$
\Phi_{r}(x)=\left\{u \in C: f(u, v)+\langle A(u, u), \eta(v, u)\rangle+\varphi(v)+\frac{1}{r}\langle v-u, J(u-x)\rangle \geq \varphi(u), \forall v \in C\right\},
$$

for all $x \in E$. Assume that

(i) $\eta(x, y)+\eta(y, x)=0$ for all $x, y \in C$;

(ii) for any fixed $u, v, w \in C$, the mapping $x \mapsto\langle A(v, w), \eta(x, u)\rangle$ is convex and lower semicontinuous;

(iii) for each $x \in C, A(x, \cdot): C \rightarrow E^{*}$ is finite-dimensional continuous: that is, for any finitedimensional subspace $F \subset E^{* *}, A(x, \cdot): C \cap F \rightarrow E^{*}$ is continuous;

(iv) $\xi: E^{* *} \rightarrow \mathcal{R}$ is convex lower semicontinuous;

(v) for any $x, y \in C, \xi(x-y)+\xi(y-x) \geq 0$;

(vi) for any $x, y \in C, A(x, y)=A(y, x)$.

Then, the following holds:

(1) $\Phi_{r}$ is single-valued;

(2) $\left\langle\Phi_{r} x-\Phi_{r} y, J\left(\Phi_{r} x-x\right)\right\rangle \leq\left\langle\Phi_{r} x-\Phi_{r} y, J\left(\Phi_{r} y-y\right)\right\rangle$ for all $x, y \in E$;

(3) $F\left(\Phi_{r}\right)=\operatorname{GMEP}(f, A, \eta, \varphi)$;

(4) $\operatorname{GMEP}(f, A, \eta, \varphi)$ is nonempty, closed, and convex.

Proof. For each $x \in E^{* *}$, by Lemma 2.10, we conclude that $\Phi_{r}(x)$ is nonempty.

(1) We prove that $\Phi_{r}$ is single-valued. Indeed, for $x \in E^{* *}$ and $r>0$, let $z_{1}, z_{2} \in \Phi_{r}(x)$. Then,

$$
\begin{aligned}
& f\left(z_{1}, v\right)+\left\langle A\left(z_{1}, z_{1}\right), \eta\left(v, z_{1}\right)\right\rangle+\varphi(v)+\frac{1}{r}\left\langle v-z_{1}, J\left(z_{1}-x\right)\right\rangle \geq \varphi\left(z_{1}\right), \quad \forall v \in C, \\
& f\left(z_{2}, v\right)+\left\langle A\left(z_{2}, z_{2}\right), \eta\left(v, z_{2}\right)\right\rangle+\varphi(v)+\frac{1}{r}\left\langle v-z_{2}, J\left(z_{2}-x\right)\right\rangle \geq \varphi\left(z_{2}\right), \quad \forall v \in C .
\end{aligned}
$$

Hence,

$$
\begin{aligned}
& f\left(z_{1}, z_{2}\right)+\left\langle A\left(z_{1}, z_{1}\right), \eta\left(z_{2}, z_{1}\right)\right\rangle+\varphi\left(z_{2}\right)+\frac{1}{r}\left\langle z_{2}-z_{1}, J\left(z_{1}-x\right)\right\rangle \geq \varphi\left(z_{1}\right), \\
& f\left(z_{2}, z_{1}\right)+\left\langle A\left(z_{2}, z_{2}\right), \eta\left(z_{1}, z_{2}\right)\right\rangle+\varphi\left(z_{1}\right)+\frac{1}{r}\left\langle z_{1}-z_{2}, J\left(z_{2}-x\right)\right\rangle \geq \varphi\left(z_{2}\right) .
\end{aligned}
$$

Adding the two inequalities, from (i) we have

$$
f\left(z_{2}, z_{1}\right)+f\left(z_{1}, z_{2}\right)+\left\langle A\left(z_{1}, z_{1}\right)-A\left(z_{2}, z_{2}\right), \eta\left(z_{2}, z_{1}\right)\right\rangle+\frac{1}{r}\left\langle z_{2}-z_{1}, J\left(z_{1}-x\right)-J\left(z_{2}-x\right)\right\rangle \geq 0 .
$$


From (A2), we have

$$
\left\langle A\left(z_{1}, z_{1}\right)-A\left(z_{2}, z_{2}\right), \eta\left(z_{2}, z_{1}\right)\right\rangle+\frac{1}{r}\left\langle z_{2}-z_{1}, J\left(z_{1}-x\right)-J\left(z_{2}-x\right)\right\rangle \geq 0 .
$$

That is,

$$
\frac{1}{r}\left\langle z_{2}-z_{1}, J\left(z_{1}-x\right)-J\left(z_{2}-x\right)\right\rangle \geq\left\langle A\left(z_{2}, z_{2}\right)-A\left(z_{1}, z_{1}\right), \eta\left(z_{2}, z_{1}\right)\right\rangle .
$$

Calculating the right-hand side of (3.22), we have

$$
\begin{aligned}
&\left\langle A\left(z_{2}, z_{2}\right)-A\left(z_{1}, z_{1}\right), \eta\left(z_{2}, z_{1}\right)\right\rangle \\
&=\left\langle A\left(z_{2}, z_{2}\right)-A\left(z_{2}, z_{1}\right)+A\left(z_{2}, z_{1}\right)-A\left(z_{1}, z_{2}\right)+A\left(z_{1}, z_{2}\right)-A\left(z_{1}, z_{1}\right), \eta\left(z_{2}, z_{1}\right)\right\rangle \\
&=\left\langle A\left(z_{2}, z_{2}\right)-A\left(z_{2}, z_{1}\right), \eta\left(z_{2}, z_{1}\right)\right\rangle+\left\langle A\left(z_{2}, z_{1}\right)-A\left(z_{1}, z_{2}\right), \eta\left(z_{2}, z_{1}\right)\right\rangle \\
&+\left\langle A\left(z_{1}, z_{2}\right)-A\left(z_{1}, z_{1}\right), \eta\left(z_{2}, z_{1}\right)\right\rangle \\
& \geq 2 \xi\left(z_{2}-z_{1}\right)+\left\langle A\left(z_{2}, z_{1}\right)-A\left(z_{1}, z_{2}\right), \eta\left(z_{2}, z_{1}\right)\right\rangle,
\end{aligned}
$$

and so,

$$
\frac{1}{r}\left\langle z_{2}-z_{1}, J\left(z_{1}-x\right)-J\left(z_{2}-x\right)\right\rangle \geq 2 \xi\left(z_{2}-z_{1}\right)+\left\langle A\left(z_{2}, z_{1}\right)-A\left(z_{1}, z_{2}\right), \eta\left(z_{2}, z_{1}\right)\right\rangle .
$$

In (3.24) exchanging the position of $z_{1}$ and $z_{2}$, we get

$$
\frac{1}{r}\left\langle z_{1}-z_{2}, J\left(z_{2}-x\right)-J\left(z_{1}-x\right)\right\rangle \geq 2 \xi\left(z_{1}-z_{2}\right)+\left\langle A\left(z_{1}, z_{2}\right)-A\left(z_{2}, z_{1}\right), \eta\left(z_{1}, z_{2}\right)\right\rangle .
$$

Adding the inequalities (3.24) and (3.25) and using (v) and (vi), we have

$$
\left\langle z_{2}-z_{1}, J\left(z_{1}-x\right)-J\left(z_{2}-x\right)\right\rangle \geq r\left(\xi\left(z_{2}-z_{1}\right)+\xi\left(z_{1}-z_{2}\right)\right) \geq 0 .
$$

Hence,

$$
0 \leq\left\langle z_{2}-z_{1}, J\left(z_{1}-x\right)-J\left(z_{2}-x\right)\right\rangle=\left\langle\left(z_{2}-x\right)-\left(z_{1}-x\right), J\left(z_{1}-x\right)-J\left(z_{2}-x\right)\right\rangle .
$$

Since $J$ is monotone and $E^{* *}$ is strictly convex, we obtain that $z_{1}-x=z_{2}-x$ and hence $z_{1}=z_{2}$. Therefore, $\Phi_{r}$ is single-valued. 
(2) For $x, y \in C$, we have

$$
\begin{aligned}
& f\left(\Phi_{r} x, \Phi_{r} y\right)+\left\langle A\left(\Phi_{r} x, \Phi_{r} x\right), \eta\left(\Phi_{r} y, \Phi_{r} x\right)\right\rangle+\varphi\left(\Phi_{r} y\right)-\varphi\left(\Phi_{r} x\right)+\frac{1}{r}\left\langle\Phi_{r} y-\Phi_{r} x, J\left(\Phi_{r} x-x\right)\right\rangle \geq 0 \\
& f\left(\Phi_{r} y, \Phi_{r} x\right)+\left\langle A\left(\Phi_{r} y, \Phi_{r} y\right), \eta\left(\Phi_{r} x, \Phi_{r} y\right)\right\rangle+\varphi\left(\Phi_{r} x\right)-\varphi\left(\Phi_{r} y\right)+\frac{1}{r}\left\langle\Phi_{r} x-\Phi_{r} y, J\left(\Phi_{r} y-y\right)\right\rangle \geq 0
\end{aligned}
$$

Adding the above two inequalities and by (i) and (A2), we get

$$
\left\langle A\left(\Phi_{r} x, \Phi_{r} x\right)-A\left(\Phi_{r} y, \Phi_{r} y\right), \eta\left(\Phi_{r} y, \Phi_{r} x\right)\right\rangle+\frac{1}{r}\left\langle\Phi_{r} y-\Phi_{r} x, J\left(\Phi_{r} x-x\right)-J\left(\Phi_{r} y-y\right)\right\rangle \geq 0
$$

that is

$$
\frac{1}{r}\left\langle\Phi_{r} y-\Phi_{r} x, J\left(\Phi_{r} x-x\right)-J\left(\Phi_{r} y-y\right)\right\rangle \geq\left\langle A\left(\Phi_{r} y, \Phi_{r} y\right)-A\left(\Phi_{r} x, \Phi_{r} x\right), \eta\left(\Phi_{r} y, \Phi_{r} x\right)\right\rangle .
$$

After calculating (3.30), we have

$$
\begin{aligned}
\frac{1}{r}\left\langle\Phi_{r} y-\Phi_{r} x, J\left(\Phi_{r} x-x\right)-J\left(\Phi_{r} y-y\right)\right\rangle \geq & 2 \xi\left(\Phi_{r} y, \Phi_{r} x\right) \\
& +\left\langle A\left(\Phi_{r} y, \Phi_{r} x\right)-A\left(\Phi_{r} x, \Phi_{r} y\right), \eta\left(\Phi_{r} y, \Phi_{r} x\right)\right\rangle .
\end{aligned}
$$

In (3.30), exchanging the position of $\Phi_{r} x$ and $\Phi_{r} y$, we get

$$
\begin{aligned}
\frac{1}{r}\left\langle\Phi_{r} x-\Phi_{r} y, J\left(\Phi_{r} y-y\right)-J\left(\Phi_{r} x-x\right)\right\rangle \geq & 2 \xi\left(\Phi_{r} x, \Phi_{r} y\right) \\
& +\left\langle A\left(\Phi_{r} x, \Phi_{r} y\right)-A\left(\Phi_{r} y, \Phi_{r} x\right), \eta\left(\Phi_{r} x, \Phi_{r} y\right)\right\rangle
\end{aligned}
$$

Adding the inequalities (3.31) and (3.32), use (i) and (vi), we have

$$
\left\langle\Phi_{r} y-\Phi_{r} x, J\left(\Phi_{r} x-x\right)-J\left(\Phi_{r} y-y\right)\right\rangle \geq r\left(\xi\left(\Phi_{r} x, \Phi_{r} y\right)+\xi\left(\Phi_{r} y, \Phi_{r} x\right)\right)
$$

It follows from (iv) that

$$
\left\langle\Phi_{r} y-\Phi_{r} x, J\left(\Phi_{r} x-x\right)-J\left(\Phi_{r} y-y\right)\right\rangle \geq 0
$$


Hence,

$$
\left\langle\Phi_{r} x-\Phi_{r} y, J\left(\Phi_{r} x-x\right)\right\rangle \leq\left\langle\Phi_{r} x-\Phi_{r} y, J\left(\Phi_{r} y-y\right)\right\rangle .
$$

(3) Next, we show that $F\left(\Phi_{r}\right)=\operatorname{GMEP}(f, A, \eta, \varphi)$. Indeed, we have the following:

$$
\begin{aligned}
u \in F\left(\Phi_{r}\right) & \Longleftrightarrow u=\Phi_{r} u \\
& \Longleftrightarrow f(u, v)+\langle A(u, u), \eta(v, u)\rangle+\varphi(v)+\frac{1}{r}\langle v-u, J(u-u)\rangle \geq \varphi(u), \quad \forall v \in C \\
& \Longleftrightarrow f(u, v)+\langle A(u, u), \eta(v, u)\rangle+\varphi(v) \geq \varphi(u), \quad \forall v \in C \\
& \Longleftrightarrow u \in \operatorname{GMEP}(f, A, \eta, \varphi) .
\end{aligned}
$$

Hence, $F\left(\Phi_{r}\right)=\operatorname{GMEP}(f, A, \eta, \varphi)$.

(4) Finally, we prove that $\operatorname{GMEP}(f, A, \eta, \varphi)$ is nonempty, closed, and convex. For each $v \in C$, we define the multivalued mapping $G: C \rightarrow 2^{E^{* *}}$ by

$$
G(v)=\{u \in C: f(u, v)+\langle A(u, u), \eta(v, u)\rangle+\varphi(v) \geq \varphi(u)\}
$$

Since $v \in G(v)$, we have $G(v) \neq \emptyset$. We prove that $G$ is a KKM mapping on $C$. Suppose that there exists a finite subset $\left\{z_{1}, z_{2}, \ldots, z_{m}\right\}$ of $C$, and $\alpha_{i}>0$ with $\sum_{i=1}^{m} \alpha_{i}=1$ such that $\widehat{z}=$ $\sum_{i=1}^{m} \alpha_{i} z_{i} \notin G\left(z_{i}\right)$ for all $i=1,2, \ldots, m$. Then

$$
f\left(\widehat{z}, z_{i}\right)+\left\langle A(\widehat{z}, \widehat{z}), \eta\left(z_{i}, \widehat{z}\right)\right\rangle+\varphi\left(z_{i}\right)-\varphi(\widehat{z})<0, \quad i=1,2, \ldots, m
$$

From (A1), (A4), (ii), and the convexity of $\varphi$, we have

$$
\begin{aligned}
0 & =f(\widehat{z}, \widehat{z})+\langle A(\widehat{z}, \widehat{z}), \eta(\widehat{z}, \widehat{z})\rangle+\varphi(\widehat{z})-\varphi(\widehat{z}) \\
& =f\left(\widehat{z}, \sum_{i=1}^{m} \alpha_{i} z_{i}\right)+\left\langle A(\widehat{z}, \widehat{z}), \eta\left(\sum_{i=1}^{m} \alpha_{i} z_{i}, \widehat{z}\right)\right\rangle+\varphi\left(\sum_{i=1}^{m} \alpha_{i} z_{i}\right)-\varphi(\widehat{z}) \\
& \leq \sum_{i=1}^{m} \alpha_{i}\left(f\left(\widehat{z}, z_{i}\right)+\left\langle A(\widehat{z}, \widehat{z}), \eta\left(z_{i}, \widehat{z}\right)\right\rangle+\varphi\left(z_{i}\right)-\varphi(\widehat{z})\right) \\
& <0
\end{aligned}
$$

which is a contradiction. Thus, $G$ is a KKM mapping on $C$.

Next, we prove that $G(y)$ is closed for each $y \in C$. For any $y \in C$, let $\left\{x_{n}\right\}$ be any sequence in $G(y)$ such that $x_{n} \rightarrow x_{0}$. We claim that $x_{0} \in G(y)$. Then, for each $y \in C$, we have

$$
f\left(x_{n}, y\right)+\left\langle A\left(x_{n}, x_{n}\right), \eta\left(y, x_{n}\right)\right\rangle+\varphi(y) \geq \varphi\left(x_{n}\right) .
$$


By monotonicity of $A$, we obtain that

$$
f\left(x_{n}, y\right)+\left\langle A\left(x_{n}, y\right), \eta\left(y, x_{n}\right)\right\rangle+\varphi(y) \geq \varphi\left(x_{n}\right)+\xi\left(y-x_{n}\right) .
$$

By (A3), (i), (ii), (iv), lower semicontinuity of $\varphi$, and the complete continuity of $A$, we obtain the following

$$
\begin{aligned}
\varphi\left(x_{0}\right)+\left\langle A\left(x_{0}, y\right), \eta\left(x_{0}, y\right)\right\rangle & \leq \liminf _{n \rightarrow \infty} \varphi\left(x_{n}\right)+\liminf _{n \rightarrow \infty}\left\langle A\left(x_{n}, y\right), \eta\left(x_{n}, y\right)\right\rangle \\
& \leq \liminf _{n \rightarrow \infty}\left(\varphi\left(x_{n}\right)+\left\langle A\left(x_{n}, y\right), \eta\left(x_{n}, y\right)\right\rangle\right) \\
& =\liminf _{n \rightarrow \infty}\left(\varphi\left(x_{n}\right)-\left\langle A\left(x_{n}, y\right), \eta\left(y, x_{n}\right)\right\rangle\right) \\
& \leq \limsup _{n \rightarrow \infty}\left(\varphi\left(x_{n}\right)-\left\langle A\left(x_{n}, y\right), \eta\left(y, x_{n}\right)\right\rangle\right) \\
& \leq \limsup _{n \rightarrow \infty}\left(f\left(x_{n}, y\right)+\varphi(y)-\xi\left(y-x_{n}\right)\right) \\
& \leq f\left(x_{0}, y\right)+\varphi(y)-\xi\left(y-x_{0}\right) .
\end{aligned}
$$

Hence,

$$
f\left(x_{0}, y\right)+\left\langle A\left(x_{0}, y\right), \eta\left(y, x_{0}\right)\right\rangle+\varphi(y) \geq \varphi\left(x_{0}\right)+\xi\left(y-x_{0}\right), \quad \forall y \in C
$$

From Lemma 2.9, we have

$$
f\left(x_{0}, y\right)+\left\langle A\left(x_{0}, x_{0}\right), \eta\left(y, x_{0}\right)\right\rangle+\varphi(y) \geq \varphi\left(x_{0}\right), \quad \forall y \in C
$$

This shows that $x_{0} \in G(y)$, and hence $G(y)$ is closed for each $y \in C$. Thus, $\operatorname{GMEP}(f, A, \eta, \varphi)=$ $\bigcap_{y \in C} G(y)$ is also closed.

Next, we observe that $G(y)$ is weakly compact. In fact, since $C$ is bounded, closed, and convex, we also have $G(y)$, which is weakly compact in the weak topology. By Lemma 2.6, we can conclude that $\bigcap_{y \in C} G(y)=\operatorname{GMEP}(f, A, \eta, \varphi) \neq \emptyset$.

Finally, we prove that $\operatorname{GMEP}(f, A, \eta, \varphi)$ is convex. In fact, let $u, v \in F\left(\Phi_{r}\right)$, and $z_{t}=$ $t u+(1-t) v$ for $t \in(0,1)$. From (2), we know that

$$
\left\langle\Phi_{r} u-\Phi_{r} z_{t}, J\left(\Phi_{r} z_{t}-z_{t}\right)-J\left(\Phi_{r} u-u\right)\right\rangle \geq 0
$$

This yields that

$$
\left\langle u-\Phi_{r} z_{t}, J\left(\Phi_{r} z_{t}-z_{t}\right)\right\rangle \geq 0
$$

Similarly, we also have

$$
\left\langle v-\Phi_{r} z_{t}, J\left(\Phi_{r} z_{t}-z_{t}\right)\right\rangle \geq 0 .
$$


It follows from (3.46) and (3.47) that

$$
\begin{aligned}
\left\|z_{t}-\Phi_{r} z_{t}\right\|^{2} & =\left\langle z_{t}-\Phi_{r} z_{t}, J\left(z_{t}-\Phi_{r} z_{t}\right)\right\rangle \\
& =t\left\langle u-\Phi_{r} z_{t}, J\left(z_{t}-\Phi_{r} z_{t}\right)\right\rangle+(1-t)\left\langle v-\Phi_{r} z_{t}, J\left(z_{t}-\Phi_{r} z_{t}\right)\right\rangle \\
& \leq 0 .
\end{aligned}
$$

Hence, $z_{t} \in F\left(\Phi_{r}\right)=\operatorname{GMEP}(f, A, \eta, \varphi)$ and hence $\operatorname{GMEP}(f, A, \eta, \varphi)$ is convex. This completes the proof.

If $E$ is reflexive (i.e., $E=E^{* *}$ ) smooth and strictly convex, then the following result can be derived as a corollary of Theorem 3.5

Corollary 3.6. Let $E$ be a reflexive smooth and strictly convex Banach space, let $C$ be a nonempty, bounded, closed, and convex subset of $E$, and let $A: C \times C \rightarrow E^{*}$ be a relaxed $\eta-\xi$ semimonotone mapping. Let $f$ be a bifunction from $C \times C$ to $R$ satisfying (A1)-(A4) and let $\varphi$ be a lower semicontinuous and convex function from $C$ to $R$. Let $r>0$ and $z \in C$ and define a mapping $\Phi_{r}: E \rightarrow C$ as follows:

$$
\Phi_{r}(x)=\left\{u \in C: f(u, v)+\langle A(u, u), \eta(v, u)\rangle+\varphi(v)+\frac{1}{r}\langle v-u, J(u-x)\rangle \geq \varphi(u), \forall v \in C\right\}
$$

for all $x \in E$. Assume that

(i) $\eta(x, y)+\eta(y, x)=0$ for all $x, y \in C$;

(ii) for any fixed $u, v, w \in C$, the mapping $x \mapsto\langle A(v, w), \eta(x, u)\rangle$ is convex and lower semicontinuous;

(iii) for each $x \in C, A(x, \cdot): C \rightarrow E^{*}$ is finite-dimensional continuous;

(iv) $\xi: E \rightarrow R$ is convex lower semicontinuous;

(v) for any $x, y \in C, \xi(x-y)+\xi(y-x) \geq 0$;

(vi) for any $x, y \in C, A(x, y)=A(y, x)$.

Then, the following holds:

(1) $\Phi_{r}$ is single-valued;

(2) $\left\langle\Phi_{r} x-\Phi_{r} y, J\left(\Phi_{r} x-x\right)\right\rangle \leq\left\langle\Phi_{r} x-\Phi_{r} y, J\left(\Phi_{r} y-y\right)\right\rangle$ for all $x, y \in E$;

(3) $F\left(\Phi_{r}\right)=\operatorname{GMEP}(f, A, \eta, \varphi)$;

(4) $\operatorname{GMEP}(f, A, \eta, \varphi)$ is nonempty, closed, and convex.

\section{Strong Convergence Theorems}

In this section, we prove a strong convergence theorem by using a hybrid projection algorithm for an asymptotically nonexpansive mapping in a uniformly convex and smooth Banach space. 
Theorem 4.1. Let E be a real Banach space with the smooth and uniformly convex second dual space $E^{* *}$, let $C$ be a nonempty, bounded, closed, and convex subset of $E^{* *}$. Let $f$ be a bifunction from $C \times C$ to $\mathcal{R}$ satisfying (A1)-(A4), and let $\varphi$ be a lower semicontinuous and convex function from $C$ to $R$. Let $A: C \times C \rightarrow E^{*}$ be a relaxed $\eta-\xi$ semi-monotone and let $S: C \rightarrow C$ be an asymptotically nonexpansive mapping with a sequence $\left\{k_{n}\right\} \subset[1, \infty)$ such that $k_{n} \rightarrow 1$ as $n \rightarrow \infty$. Assume that $\Omega:=F(S) \cap \operatorname{GMEP}(f, A, \eta, \varphi) \neq \emptyset$. Let $\left\{x_{n}\right\}$ be a sequence in $C$ generated by

$$
\begin{aligned}
& x_{0} \in C, \quad D_{0}=C_{0}=C, \\
& C_{n}=\overline{\mathrm{co}}\left\{z \in C_{n-1}:\left\|z-S^{n} z\right\| \leq t_{n}\left\|x_{n}-S^{n} x_{n}\right\|\right\}, \quad n \geq 1, \\
& u_{n} \in C \text { such that } \\
& f\left(u_{n}, y\right)+\varphi(y)+\left\langle A\left(u_{n}, u_{n}\right), \eta\left(y, u_{n}\right)\right\rangle+\frac{1}{r_{n}}\left\langle y-u_{n}, J\left(u_{n}-x_{n}\right)\right\rangle \geq \varphi\left(u_{n}\right), \quad \forall y \in C, n \geq 0, \\
& D_{n}=\left\{z \in D_{n-1}:\left\langle u_{n}-z, J\left(x_{n}-u_{n}\right)\right\rangle \geq 0\right\}, \quad n \geq 1, \\
& x_{n+1}=P_{C_{n} \cap D_{n}} x_{0}, \quad n \geq 0,
\end{aligned}
$$

where $\left\{t_{n}\right\}$ and $\left\{r_{n}\right\}$ are real sequences in $(0,1)$ such that $\lim _{n \rightarrow \infty} t_{n}=0$, and $\lim _{\inf _{n \rightarrow \infty}} r_{n}>0$. Then $\left\{x_{n}\right\}$ converges strongly, as $n \rightarrow \infty$, to $P_{\Omega} x_{0}$.

Proof. Firstly, we rewrite the (4.1) as follows:

$$
\begin{aligned}
& x_{0} \in C, \quad D_{0}=C_{0}=C, \\
& C_{n}=\overline{c 0}\left\{z \in C_{n-1}:\left\|z-S^{n} z\right\| \leq t_{n}\left\|x_{n}-S^{n} x_{n}\right\|\right\}, \quad n \geq 0, \\
& D_{n}=\left\{z \in D_{n-1}:\left\langle\Phi_{r_{n}} x_{n}-z, J\left(x_{n}-\Phi_{r_{n}} x_{n}\right)\right\rangle \geq 0\right\}, \quad n \geq 1, \\
& x_{n+1}=P_{C_{n} \cap D_{n}} x_{0}, \quad n \geq 0,
\end{aligned}
$$

where $\Phi_{r}$ is the mapping defined by

$$
\Phi_{r}(x)=\left\{z \in C: f(z, y)+\langle A(z, z), \eta(y, z)\rangle+\varphi(y)+\frac{1}{r}\langle y-z, J(z-x)\rangle \geq \varphi(z), \forall y \in C\right\}
$$

We first show that the sequence $\left\{x_{n}\right\}$ is well defined. It is easy to verify that $C_{n} \cap D_{n}$ is closed and convex and $\Omega \subset C_{n}$ for all $n \geq 0$. Next, we prove that $\Omega \subset C_{n} \cap D_{n}$. Since $D_{0}=C$, we also have $\Omega \subset C_{0} \cap D_{0}$. Suppose that $\Omega \subset C_{k-1} \cap D_{k-1}$ for $k \geq 2$. It follows from Theorem 3.5 (2) that

$$
\left\langle\Phi_{r_{k}} x_{k}-\Phi_{r_{k}} u, J\left(\Phi_{r_{k}} u-u\right)-J\left(\Phi_{r_{k}} x_{k}-x_{k}\right)\right\rangle \geq 0
$$


for all $u \in \Omega$. This implies that

$$
\left\langle\Phi_{r_{k}} x_{k}-u, J\left(x_{k}-\Phi_{r_{k}} x_{k}\right)\right\rangle \geq 0,
$$

for all $u \in \Omega$. Hence $\Omega \subset D_{k}$. By the mathematical induction, we get that $\Omega \subset C_{n} \cap D_{n}$ for each $n \geq 0$, and hence $\left\{x_{n}\right\}$ is welldefined. Put $w=P_{\Omega} x_{0}$. Since $\Omega \subset C_{n} \cap D_{n}$ and $x_{n+1}=P_{C_{n} \cap D_{n}}$, we have

$$
\left\|x_{n+1}-x_{0}\right\| \leq\left\|w-x_{0}\right\|, \quad n \geq 0
$$

Since $x_{n+2} \in D_{n+1} \subset D_{n}$ and $x_{n+1}=P_{C_{n} \cap D_{n}} x_{0}$, we have

$$
\left\|x_{n+1}-x_{0}\right\| \leq\left\|x_{n+2}-x_{0}\right\|
$$

Since $\left\{\left\|x_{n}-x_{0}\right\|\right\}$ is bounded, we have $\lim _{n \rightarrow \infty}\left\|x_{n}-x_{0}\right\|=d$ for some a constant $d$. Moreover, by the convexity of $D_{n}$, we also have $(1 / 2)\left(x_{n+1}+x_{n+2}\right) \in D_{n}$ and hence

$$
\left\|x_{0}-x_{n+1}\right\| \leq\left\|x_{0}-\frac{x_{n+1}+x_{n+2}}{2}\right\| \leq \frac{1}{2}\left(\left\|x_{0}-x_{n+1}\right\|+\left\|x_{0}-x_{n+2}\right\|\right) .
$$

This implies that

$$
\lim _{n \rightarrow \infty}\left\|\frac{1}{2}\left(x_{0}-x_{n+1}\right)+\frac{1}{2}\left(x_{0}-x_{n+2}\right)\right\|=\lim _{n \rightarrow \infty}\left\|x_{0}-\frac{x_{n+1}+x_{n+2}}{2}\right\|=d .
$$

By Lemma 2.2, we have

$$
\lim _{n \rightarrow \infty}\left\|x_{n}-x_{n+1}\right\|=0
$$

Next, we show that

$$
\lim _{n \rightarrow \infty}\left\|x_{n}-S x_{n}\right\|=0
$$

To obtain (4.11), we need to show that $\lim _{n \rightarrow \infty}\left\|x_{n}-S^{n-k} x_{n}\right\|=0$, for all $k \in \mathcal{N}$.

Fix $k \in \mathcal{N}$ and put $m=n-k$. Since $x_{n}=P_{C_{n-1} \cap D_{n-1}} x$, we have $x_{n} \in C_{n-1} \subseteq \cdots \subseteq C_{m}$. Since $t_{m}>0$, there exist $y_{1}, \ldots, y_{N} \in C$ and nonnegative numbers $\lambda_{1}, \ldots, \lambda_{N}$ with $\lambda_{1}+\cdots+\lambda_{N}=1$ such that

$$
\left\|x_{n}-\sum_{i=1}^{N} \lambda_{i} y_{i}\right\|<t_{m}
$$


and $\left\|y_{i}-S^{m} y_{i}\right\| \leq t_{m}\left\|x_{m}-S^{m} x_{m}\right\|$ for all $i \in\{1, \ldots, N\}$. Put $M=\sup _{x \in C}\|x\|, u=P_{F(S)} x$ and $r_{0}=\sup _{n \geq 1}\left(1+k_{n}\right)\left\|x_{n}-u\right\|$. Since $C$ and $\left\{k_{m}\right\}$ are bounded, (4.12) implies

$$
\left\|x_{n}-\frac{1}{k_{m}} \sum_{i=1}^{N} \lambda_{i} y_{i}\right\| \leq\left(1-\frac{1}{k_{m}}\right)\|x\|+\frac{1}{k_{m}}\left\|x_{n}-\sum_{i=1}^{N} \lambda_{i} y_{i}\right\| \leq\left(1-\frac{1}{k_{m}}\right) M+t_{m}
$$

and $\left\|y_{i}-S^{m} y_{i}\right\| \leq t_{m}\left\|x_{m}-S^{m} x_{m}\right\| \leq t_{m}\left(1+k_{m}\right)\left\|x_{m}-u\right\| \leq r_{0} t_{m}$ for all $i \in\{1, \ldots, N\}$. Therefore,

$$
\left\|y_{i}-\frac{1}{k_{m}} S^{m} y_{i}\right\| \leq\left(1-\frac{1}{k_{m}}\right) M+r_{0} t_{m}
$$

for all $i \in\{1, \ldots, N\}$. Moreover, asymptotically nonexpansiveness of $S$ and (4.6) give that

$$
\left\|\frac{1}{k_{m}} S^{m}\left(\sum_{i=1}^{N} \lambda_{i} y_{i}\right)-S^{m} x_{n}\right\| \leq\left(1-\frac{1}{k_{m}}\right) M+t_{m}
$$

It follows from Theorem 2.4, (4.13)-(4.15) that

$$
\begin{aligned}
\left\|x_{n}-S^{m} x_{n}\right\| \leq & \left\|x_{n}-\frac{1}{k_{m}} \sum_{i=1}^{N} \lambda_{i} y_{i}\right\|+\frac{1}{k_{m}}\left\|\sum_{i=1}^{N} \lambda_{i}\left(y_{i}-S^{m} y_{i}\right)\right\| \\
& +\frac{1}{k_{m}}\left\|\sum_{i=1}^{N} \lambda_{i} S^{m} y_{i}-S^{m}\left(\sum_{i=1}^{N} \lambda_{i} y_{i}\right)\right\|+\left\|\frac{1}{k_{m}} S^{m}\left(\sum_{i=1}^{N} \lambda_{i} y_{i}\right)-S^{m} x_{n}\right\| \\
\leq & 2\left(1-\frac{1}{k_{m}}\right) M+2 t_{m}+\frac{r_{0} t_{m}}{k_{m}}+r^{-1}\left(\max _{1 \leq i \leq j \leq N}\left(\left\|y_{i}-y_{j}\right\|-\frac{1}{k_{m}}\left\|S^{m} y_{i}-S^{m} y_{j}\right\|\right)\right) \\
\leq & 2\left(1-\frac{1}{k_{m}}\right) M+2 t_{m}+\frac{r_{0} t_{m}}{k_{m}}+r^{-1}\left(\max _{1 \leq i \leq j \leq N}\left(\left\|y_{i}-\frac{1}{k_{m}} S^{m} y_{i}\right\|+\left\|y_{j}-\frac{1}{k_{m}} S^{m} y_{j}\right\|\right)\right) \\
\leq & 2\left(1-\frac{1}{k_{m}}\right) M+2 t_{m}+\frac{r_{0} t_{m}}{k_{m}}+r^{-1}\left(2\left(1-\frac{1}{k_{m}}\right) M+2 r_{0} t_{m}\right) .
\end{aligned}
$$

Since $\lim _{n \rightarrow \infty} k_{n}=1$ and $\lim _{n \rightarrow \infty} t_{n}=0$, it follows from the last inequality that $\lim _{n \rightarrow \infty} \| x_{n}-$ $S^{m} x_{n} \|=0$. We have that

$$
\begin{aligned}
\left\|x_{n}-S x_{n}\right\| & =\left\|x_{n}-S^{n-1} x_{n}\right\|+\left\|S^{n-1} x_{n}-S x_{n}\right\| \\
& \leq\left\|x_{n}-S^{n-1} x_{n}\right\|+k_{1}\left\|S^{n-2} x_{n}-x_{n}\right\| \longrightarrow 0 \text { as } n \longrightarrow \infty
\end{aligned}
$$

Since $\left\{x_{n}\right\}$ is bounded, there exists a subsequence $\left\{x_{n_{i}}\right\}$ of $\left\{x_{n}\right\}$ such that $x_{n_{i}} \rightarrow \tilde{x} \in C$. Therefore, we obtain $\tilde{x} \in F(S)$. Next, we show that $\tilde{x} \in \operatorname{GMEP}(f, A, \eta, \varphi)$. By the construction of $D_{n}$, we see from Theorem 2.1 that $\Phi_{r_{n}} x_{n}=P_{D_{n}} x_{n}$. Since $x_{n+1} \in D_{n}$, we get

$$
\left\|x_{n}-\Phi_{r_{n}} x_{n}\right\| \leq\left\|x_{n}-x_{n+1}\right\| \longrightarrow 0 .
$$


From (C2), we also have

$$
\frac{1}{r_{n}}\left\|J\left(x_{n}-\Phi_{r_{n}} x_{n}\right)\right\|=\frac{1}{r_{n}}\left\|x_{n}-\Phi_{r_{n}} x_{n}\right\| \longrightarrow 0
$$

as $n \rightarrow \infty$. By (4.19), we also have $\Phi_{r_{n_{i}}} x_{n_{i}}-\tilde{x}$. By the definition of $\Phi_{r_{n_{i}}}$, for each $y \in C$, we obtain

$$
\begin{gathered}
f\left(\Phi_{r_{n_{i}}} x_{n_{i}}, y\right)+\left\langle A\left(\Phi_{r_{n_{i}}} x_{n_{i}}, \Phi_{r_{n_{i}}} x_{n_{i}}\right), \eta\left(y, \Phi_{r_{n_{i}}} x_{n_{i}}\right)\right\rangle+\varphi(y) \\
+\frac{1}{r_{n_{i}}}\left\langle y-\Phi_{r_{n_{i}}} x_{n_{i}}, J\left(\Phi_{r_{n_{i}}} x_{n_{i}}-x_{n_{i}}\right)\right\rangle \geq \varphi\left(\Phi_{r_{n_{i}}} x_{n_{i}}\right) .
\end{gathered}
$$

By (A3), (4.19), (ii), the weakly lower semicontinuity of $\varphi$ and complete continuity of $A$ we have

$$
\begin{aligned}
\varphi(\tilde{x}) \leq & \liminf _{i \rightarrow \infty} \varphi\left(\Phi_{r_{n_{i}}} x_{n_{i}}\right) \\
\leq & \liminf _{i \rightarrow \infty} f\left(\Phi_{r_{n_{i}}} x_{n_{i}}, y\right)+\liminf _{i \rightarrow \infty}\left\langle A\left(\Phi_{r_{n_{i}}} x_{n_{i}}, \Phi_{r_{n_{i}}} x_{n_{i}}\right), \eta\left(y, \Phi_{r_{n_{i}}} x_{n_{i}}\right)\right\rangle \\
& +\varphi(y)+\liminf _{i \rightarrow \infty} \frac{1}{r_{n_{i}}}\left\langle y-\Phi_{r_{n_{i}}} x_{n_{i}} J\left(\Phi_{r_{n_{i}}} x_{n_{i}}-x_{n_{i}}\right)\right\rangle \\
& \leq f(\tilde{x}, y)+\varphi(y)+\langle A(\tilde{x}, \tilde{x}), \eta(y, \tilde{x})\rangle .
\end{aligned}
$$

Hence,

$$
f(\tilde{x}, y)+\varphi(y)+\langle A(\tilde{x}, \tilde{x}), \eta(y, \tilde{x})\rangle \geq \varphi(\tilde{x}) .
$$

This shows that $\tilde{x} \in \operatorname{GMEP}(f, A, \eta, \varphi)$, and hence $\tilde{x} \in \Omega:=F(S) \cap \operatorname{GMEP}(f, A, \eta, \varphi)$.

Finally, we show that $x_{n} \rightarrow w$ as $n \rightarrow \infty$, where $w:=P_{\Omega} x_{0}$. By the weakly lower semicontinuity of the norm, it follows from (4.6) that

$$
\left\|x_{0}-w\right\| \leq\left\|x_{0}-\tilde{x}\right\| \leq \liminf _{i \rightarrow \infty}\left\|x_{0}-x_{n_{i}}\right\| \leq \limsup _{i \rightarrow \infty}\left\|x_{0}-x_{n_{i}}\right\| \leq\left\|x_{0}-w\right\|
$$

This shows that

$$
\lim _{i \rightarrow \infty}\left\|x_{0}-x_{n_{i}}\right\|=\left\|x_{0}-w\right\|=\left\|x_{0}-\tilde{x}\right\|
$$

and $\tilde{x}=w$. Since $E^{* *}$ is uniformly convex, we obtain that $x_{0}-x_{n_{i}} \rightarrow x_{0}-w$. It follows that $x_{n_{i}} \rightarrow w$. So, we have $x_{n} \rightarrow w$ as $n \rightarrow \infty$. This completes the proof.

If $S$ is a nonexpansive mapping in Theorem 4.1, then we obtain the following result concerning the problem of finding a common element of $\operatorname{GMEP}(f, A, \eta, \varphi)$ and the fixed point set of a nonexpansive mapping in a Banach space setting. 
Theorem 4.2. Let E be a real Banach space with the smooth and uniformly convex second dual space $E^{* *}$, let $C$ be a nonempty, bounded, closed, and convex subset of $E^{* *}$. Let $f$ be a bifunction from $C \times C$ to $R$ satisfying (A1)-(A4) and let $\varphi$ be a lower semicontinuous and convex function from $C$ to $R$. Let $A: C \times C \rightarrow E^{*}$ be a relaxed $\eta-\xi$ semi-monotone and let $S: C \rightarrow C$ be a nonexpansive mapping such that $\Omega:=F(S) \cap \operatorname{GMEP}(f, A, \eta, \varphi) \neq \emptyset$. Let $\left\{x_{n}\right\}$ be a sequence in $C$ generated by

$$
\begin{aligned}
& x_{0} \in C, \quad D_{0}=C_{0}=C, \\
& C_{n}=\overline{\mathrm{c}}\left\{z \in C_{n-1}:\|z-S z\| \leq t_{n}\left\|x_{n}-S x_{n}\right\|\right\}, \quad n \geq 1, \\
& u_{n} \in C \text { such that } \\
& f\left(u_{n}, y\right)+\varphi(y)+\left\langle A\left(u_{n}, u_{n}\right), \eta\left(y, u_{n}\right)\right\rangle+\frac{1}{r_{n}}\left\langle y-u_{n}, J\left(u_{n}-x_{n}\right)\right\rangle \geq \varphi\left(u_{n}\right), \quad \forall y \in C, n \geq 0, \\
& D_{n}=\left\{z \in D_{n-1}:\left\langle u_{n}-z, J\left(x_{n}-u_{n}\right)\right\rangle \geq 0\right\}, \quad n \geq 1, \\
& x_{n+1}=P_{C_{n} \cap D_{n}} x_{0}, \quad n \geq 0,
\end{aligned}
$$

where $\left\{t_{n}\right\}$ and $\left\{r_{n}\right\}$ are real sequences in $(0,1)$ such that $\lim _{n \rightarrow \infty} t_{n}=0$, and $\liminf _{n \rightarrow \infty} r_{n}>0$. Then, $\left\{x_{n}\right\}$ converges strongly, as $n \rightarrow \infty$, to $P_{\Omega} x_{0}$.

Putting $A \equiv 0$ and $\varphi \equiv 0$ in Theorem 4.1, then we have the following result in a Banach space.

Theorem 4.3. Let $E$ be a real Banach space with the smooth and uniformly convex second dual space $E^{* *}$ and let $C$ be a nonempty, bounded, closed, and convex subset of $E^{* *}$. Let $f$ be a bifunction from $C \times C$ to $R$ satisfying (A1)-(A4). Let $S: C \rightarrow C$ be an asymptotically nonexpansive mapping with a sequence $\left\{k_{n}\right\} \subset[1, \infty)$ such that $\Omega:=F(S) \cap \operatorname{EP}(f) \neq \emptyset$. Let $\left\{x_{n}\right\}$ be a sequence in $C$ generated by

$$
\begin{aligned}
& x_{0} \in C, \quad D_{0}=C_{0}=C, \\
& C_{n}=\overline{\mathrm{CO}}\left\{z \in C_{n-1}:\left\|z-S^{n} z\right\| \leq t_{n}\left\|x_{n}-S^{n} x_{n}\right\|\right\}, \quad n \geq 1, \\
& u_{n} \in C \text { such that } \\
& f\left(u_{n}, y\right)+\frac{1}{r_{n}}\left\langle y-u_{n}, J\left(u_{n}-x_{n}\right)\right\rangle \geq 0, \quad \forall y \in C, n \geq 0, \\
& D_{n}=\left\{z \in D_{n-1}:\left\langle u_{n}-z, J\left(x_{n}-u_{n}\right)\right\rangle \geq 0\right\}, \quad n \geq 1, \\
& x_{n+1}=P_{C_{n} \cap D_{n}} x_{0}, \quad n \geq 0,
\end{aligned}
$$

where $\left\{t_{n}\right\}$ and $\left\{r_{n}\right\}$ are real sequences in $(0,1)$ such that $\lim _{n \rightarrow \infty} t_{n}=0$, and $\liminf _{n \rightarrow \infty} r_{n}>0$. Then, $\left\{x_{n}\right\}$ converges strongly, as $n \rightarrow \infty$, to $P_{\Omega} x_{0}$.

Putting $f \equiv 0, A \equiv 0, \varphi \equiv 0$, and $r_{n} \equiv 1$ in Theorem 4.1 and applying Theorem 2.1, we get $x_{n}=u_{n}$. Then, we have the following new approximation method concerning the problem of finding a fixed of an asymptotically nonexpansive mapping in a Banach space. 
Theorem 4.4. Let E be a real Banach space with the smooth and uniformly convex second dual space $E^{* *}$, let $C$ be a nonempty, bounded, closed, and convex subset of $E^{* *}$. Let $S: C \rightarrow C$ be an asymptotically nonexpansive mapping with a sequence $\left\{k_{n}\right\} \subset[1, \infty)$ such that $F(S) \neq \emptyset$. Let $\left\{x_{n}\right\}$ be a sequence in $C$ generated by

$$
\begin{gathered}
x_{0} \in C, \quad C_{0}=C, \\
C_{n}=\overline{c o}\left\{z \in C_{n-1}:\left\|z-S^{n} z\right\| \leq t_{n}\left\|x_{n}-S^{n} x_{n}\right\|\right\}, \quad n \geq 1, \\
x_{n+1}=P_{C_{n}} x_{0}, \quad n \geq 0,
\end{gathered}
$$

where $\left\{t_{n}\right\}$ and $\left\{r_{n}\right\}$ is a real sequence in $(0,1)$ such that $\lim _{n \rightarrow \infty} t_{n}=0$. Then $\left\{x_{n}\right\}$ converges strongly, as $n \rightarrow \infty$, to $P_{F(S)} x_{0}$.

If $E$ is reflexive (i.e., $E=E^{* *}$ ) smooth and uniformly convex, then the following results can be derived as a corollary of Theorem 4.4.

Corollary 4.5. Let $E$ be a reflexive smooth and uniformly convex real Banach space, let $C$ be a nonempty, bounded, closed, and convex subset of $E$. Let $S: C \rightarrow C$ be an asymptotically nonexpansive mapping with a sequence $\left\{k_{n}\right\} \subset[1, \infty]$ such that $F(S) \neq \emptyset$. Let $\left\{x_{n}\right\}$ be a sequence in $C$ generated by

$$
\begin{gathered}
x_{0} \in C, \quad C_{0}=C, \\
C_{n}=\overline{\mathrm{co}}\left\{z \in C_{n-1}:\left\|z-S^{n} z\right\| \leq t_{n}\left\|x_{n}-S^{n} x_{n}\right\|\right\}, \quad n \geq 1, \\
x_{n+1}=P_{C_{n}} x_{0}, \quad n \geq 0,
\end{gathered}
$$

where $\left\{t_{n}\right\}$ and $\left\{r_{n}\right\}$ is a real sequence in $(0,1)$ such that $\lim _{n \rightarrow \infty} t_{n}=0$. Then, $\left\{x_{n}\right\}$ converges strongly, as $n \rightarrow \infty$, to $P_{F(S)} x_{0}$.

\section{Acknowledgment}

The first author is supported by the "Centre of Excellence in Mathematics" under the Commission on Higher Education, Ministry of Education, Thailand.

\section{References}

[1] Y. P. Fang and N. J. Huang, "Variational-like inequalities with generalized monotone mappings in Banach spaces," Journal of Optimization Theory and Applications, vol. 118, no. 2, pp. 327-338, 2003.

[2] Y.-Q. Chen, "On the semi-monotone operator theory and applications," Journal of Mathematical Analysis and Applications, vol. 231, no. 1, pp. 177-192, 1999.

[3] L.-C. Ceng and J.-C. Yao, "A hybrid iterative scheme for mixed equilibrium problems and fixed point problems," Journal of Computational and Applied Mathematics, vol. 214, no. 1, pp. 186-201, 2008.

[4] P. Cholamjiak and S. Suantai, "Existence and iteration for a mixed equilibrium problem and a countable family of nonexpansive mappings in Banach spaces," Computers $\mathcal{E}$ Mathematics with Applications, vol. 61, no. 9, pp. 2725-2733, 2011.

[5] Y. Yao, Y.-C. Liou, and S. M. Kang, "Two-step projection methods for a system of variational inequality problems in Banach spaces," Journal of Global Optimization. In press.

[6] Y. Yao and N. Shahzad, "Strong convergence of a proximal point algorithm with general errors," Optimization Letters. In press. 
[7] Y. Yao, R. Chen, and Y.-C. Liou, "A unified implicit algorithm for solving the triple-hierarchical constrained optimization problem," Mathematical and Computer Modelling, vol. 55, no. 3-4, pp. 15061515, 2012.

[8] Y. Yao, W. Jigang, and Y.-C. Liou, "Regularized methods for the split feasibility problem," Abstract and Applied Analysis. In press.

[9] Y. Yao, M. A. Noor, and Y.-C. Liou, "Strong convergence of a modified extra-gradient method to the minimum-norm solution of variational inequalities," Abstract and Applied Analysis, vol. 2012, Article ID 817436, 9 pages, 2012.

[10] Y. Yao, M. A. Noor, Y.-C. Liou, and S. M. Kang, "Iterative algorithms for general multi-valued variational inequalities," Abstract and Applied Analysis, vol. 2012, Article ID 768272, 10 pages, 2012.

[11] Y. Yao, Y. J. Cho, and Y.-C. Liou, "Hierarchical convergence of an implicit double-net algorithm for nonexpansive semigroups and variational inequalities," Fixed Point Theory and Applications, vol. 2011, article 101, 2011.

[12] E. Blum and W. Oettli, "From optimization and variational inequalities to equilibrium problems," The Mathematics Student, vol. 63, no. 1-4, pp. 123-145, 1994.

[13] P. L. Combettes and S. A. Hirstoaga, "Equilibrium programming in Hilbert spaces," Journal of Nonlinear and Convex Analysis, vol. 6, no. 1, pp. 117-136, 2005.

[14] A. Moudafi, "Second-order differential proximal methods for equilibrium problems," Journal of Inequalities in Pure and Applied Mathematics, vol. 4, no. 1, article 18, 2003.

[15] K. Goebel and W. A. Kirk, "A fixed point theorem for asymptotically nonexpansive mappings," Proceedings of the American Mathematical Society, vol. 35, pp. 171-174, 1972.

[16] W. R. Mann, "Mean value methods in iteration," Proceedings of the American Mathematical Society, vol. 4, pp. 506-510, 1953.

[17] S.-y. Matsushita and W. Takahashi, "Approximating fixed points of nonexpansive mappings in a Banach space by metric projections," Applied Mathematics and Computation, vol. 196, no. 1, pp. 422 $425,2008$.

[18] A. Tada and W. Takahashi, "Strong convergence theorem for an equilibrium problem and a nonexpansive mapping," in Nonlinear Analysis and Convex Analysis, pp. 609-617, Yokohama Publishers, Yokohama, Japan, 2007.

[19] A. Tada and W. Takahashi, "Weak and strong convergence theorems for a nonexpansive mapping and an equilibrium problem," Journal of Optimization Theory and Applications, vol. 133, no. 3, pp. 359-370, 2007.

[20] S. Takahashi and W. Takahashi, "Strong convergence theorem for a generalized equilibrium problem and a nonexpansive mapping in a Hilbert space," Nonlinear Analysis: Theory, Methods E Applications, vol. 69 , no. 3, pp. 1025-1033, 2008.

[21] W. Takahashi, Y. Takeuchi, and R. Kubota, "Strong convergence theorems by hybrid methods for families of nonexpansive mappings in Hilbert spaces," Journal of Mathematical Analysis and Applications, vol. 341, no. 1, pp. 276-286, 2008.

[22] P. Kumam, N. Petrot, and R. Wangkeeree, "A hybrid iterative scheme for equilibrium problems and fixed point problems of asymptotically $k$-strict pseudo-contractions," Journal of Computational and Applied Mathematics, vol. 233, no. 8, pp. 2013-2026, 2010.

[23] X. Qin, Y. J. Cho, S. M. Kang, and M. Shang, "A hybrid iterative scheme for asymptotically $k$-strict pseudo-contractions in Hilbert spaces," Nonlinear Analysis: Theory, Methods \& Applications, vol. 70, no. 5, pp. 1902-1911, 2009.

[24] H. Dehghan, "Approximating fixed points of asymptotically nonexpansive mappings in Banach spaces by metric projections," Applied Mathematics Letters, vol. 24, no. 9, pp. 1584-1587, 2011.

[25] Y. Yao and M. A. Noor, "Convergence of three-step iterations for asymptotically nonexpansive mappings," Applied Mathematics and Computation, vol. 187, no. 2, pp. 883-892, 2007.

[26] H. H. Bauschke, E. Matoušková, and S. Reich, "Projection and proximal point methods: convergence results and counterexamples," Nonlinear Analysis: Theory, Methods E Applications, vol. 56, no. 5, pp. 715-738, 2004.

[27] A. Genel and J. Lindenstrauss, "An example concerning fixed points," Israel Journal of Mathematics, vol. 22, no. 1, pp. 81-86, 1975.

[28] S. Reich, "Weak convergence theorems for nonexpansive mappings in Banach spaces," Journal of Mathematical Analysis and Applications, vol. 67, no. 2, pp. 274-276, 1979.

[29] K. Nakajo and W. Takahashi, "Strong convergence theorems for nonexpansive mappings and nonexpansive semigroups," Journal of Mathematical Analysis and Applications, vol. 279, no. 2, pp. 372 379, 2003. 
[30] H.-K. Xu, "Strong convergence of approximating fixed point sequences for nonexpansive mappings," Bulletin of the Australian Mathematical Society, vol. 74, no. 1, pp. 143-151, 2006.

[31] R. P. Agarwal, D. O'Regan, and D. R. Sahu, Fixed Point Theory for Lipschitzian-Type Mappings with Applications, vol. 6 of Topological Fixed Point Theory and Its Applications, Springer, New York, NY, USA, 2009.

[32] E. Zeidler, Nonlinear Functional Analysis and Its Applications. I: Fixed-Point Theorems, Springer, New York, NY, USA, 1986.

[33] R. E. Bruck, "On the convex approximation property and the asymptotic behavior of nonlinear contractions in Banach spaces," Israel Journal of Mathematics, vol. 38, no. 4, pp. 304-314, 1981.

[34] K. Fan, "A generalization of Tychonoff's fixed point theorem," Mathematische Annalen, vol. 142, pp. 305-310, 1960/1961.

[35] I. L. Glicksberg, "A further generalization of the Kakutani fixed theorem, with application to Nash equilibrium points," Proceedings of the American Mathematical Society, vol. 3, pp. 170-174, 1952.

[36] J. C. Yao, "Existence of generalized variational inequalities," Operations Research Letters, vol. 15, no. 1, pp. 35-40, 1994.

[37] U. Kamraksa and R. Wangkeeree, "Existence theorems and iterative approximation methods for generalized mixed equilibrium problems for a countable family of nonexpansive mappings," Journal of Global Optimization. In press. 


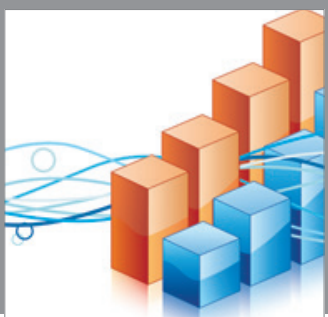

Advances in

Operations Research

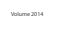

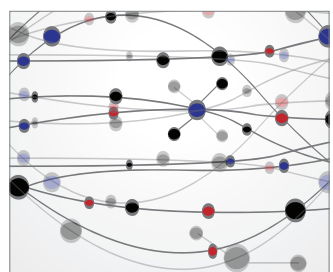

\section{The Scientific} World Journal
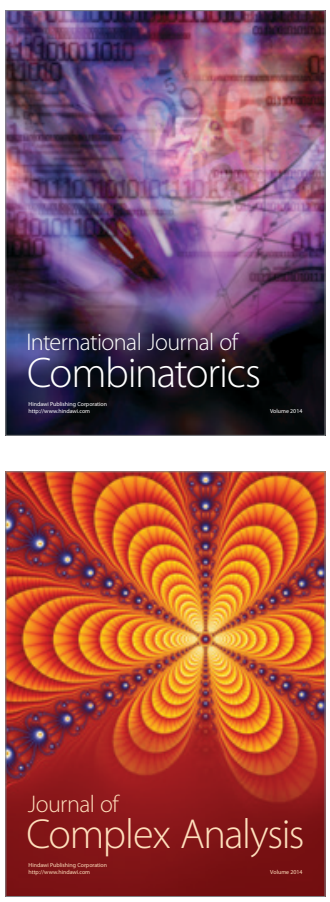

International Journal of

Mathematics and

Mathematical

Sciences
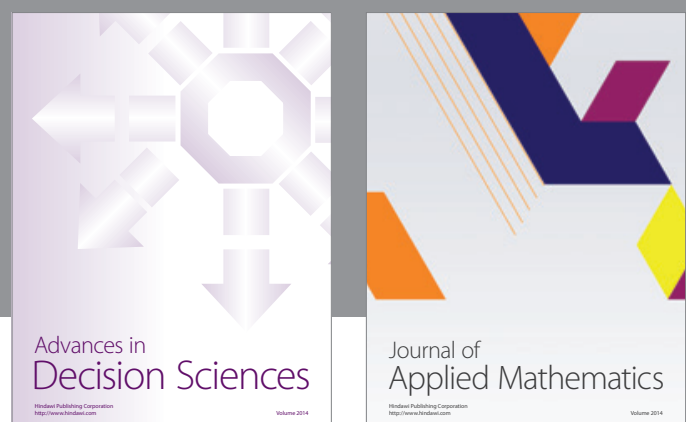

Journal of

Applied Mathematics
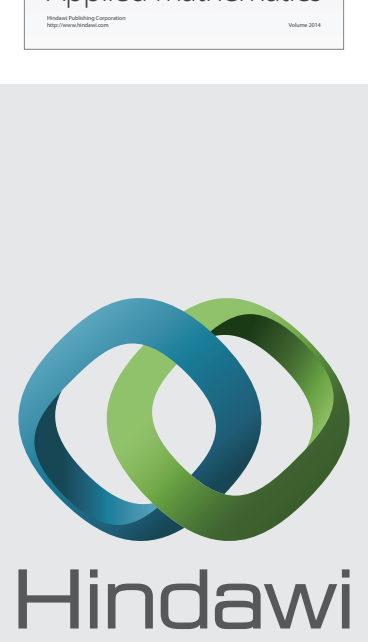

Submit your manuscripts at http://www.hindawi.com
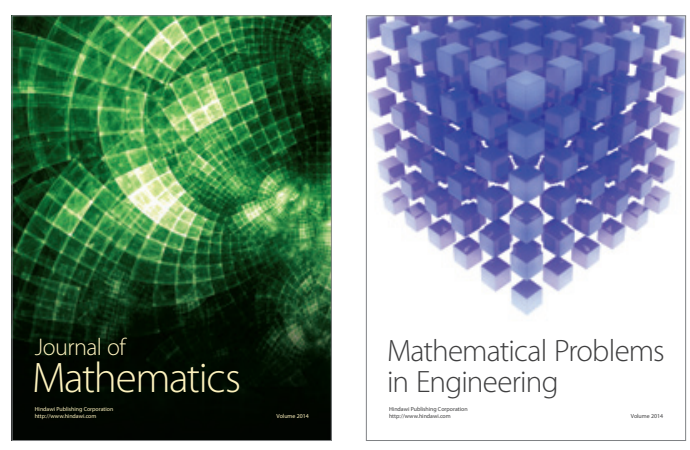

Mathematical Problems in Engineering
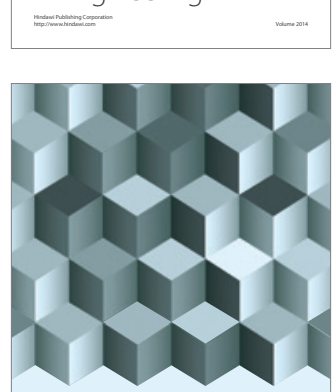

Journal of

Function Spaces
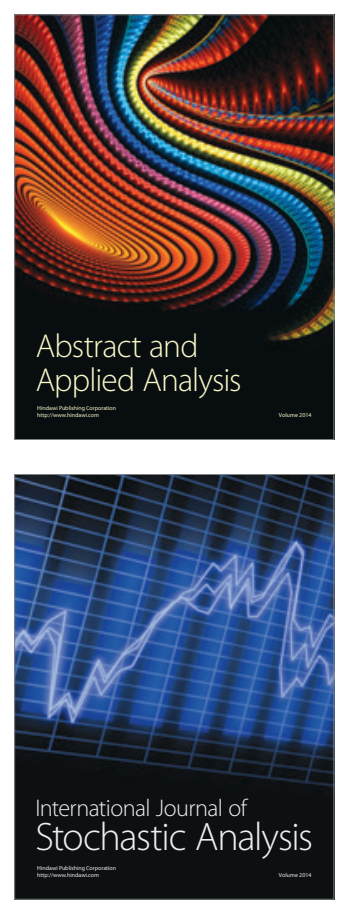

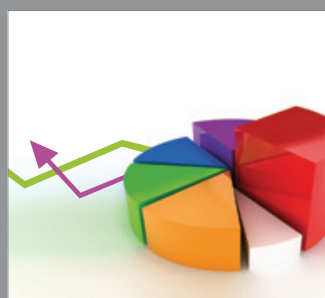

ournal of

Probability and Statistics

Promensencen
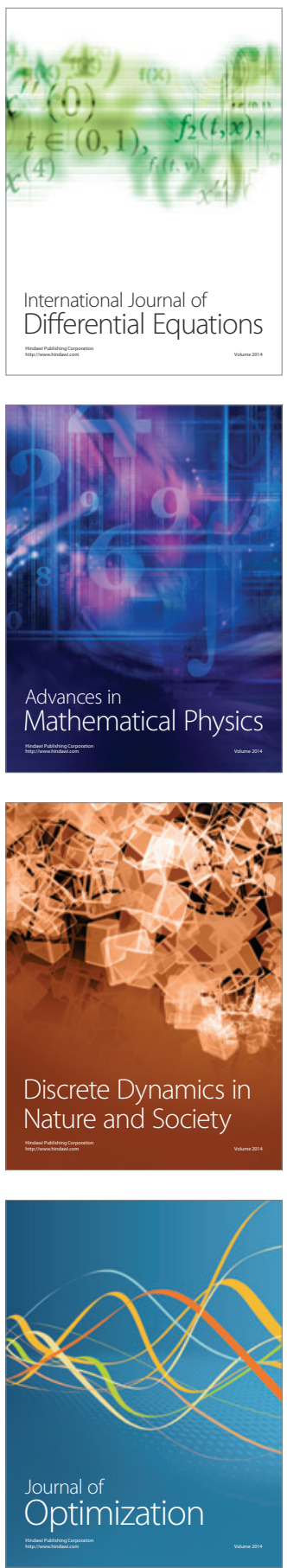